\title{
Learning vocational practice in relative social isolation: The epistemological and pedagogic practices of small business operators
}

\author{
Stephen Billett, Griffith University, Australia
}

The knowledge required for effective vocational practice arises from historical and cultural sources, with the actual requirements for performance at work being manifested in particular ways in specific workplace settings. In order to construct this knowledge (i.e., learn it), individuals need to engage with social partners, artefacts, and practices that provide access to the procedural, conceptual, and dispositional forms of the knowledge. Much is understood about how this learning progresses in situations that provide direct access to this knowledge through more experienced social partners (e.g., teachers in schools and colleges, experts in workplaces). However, many individuals (e.g., shift workers, home workers) are working and learning in relative social isolation and often in the absence of such expert partners.

Moreover, perhaps most learning occurs through experiences in working life in the absence of expert guidance. Consequently, there must be ways of learning socially derived knowledge in the absence of more experienced partners. This chapter discusses learning in relative social isolation to advance a conception of the process of learning in these kinds of situations. It does this by re-engaging with learning theorists whose ideas are informative and by elaborating these processes through explanations of small business operators' epistemological and pedagogic practices as they learnt new work tasks. In combination, both localised contributions and these workers' agency are held to be central to their learning in these circumstances. This account informs the means by which other kinds of socially isolated workers might come to know and learn through their working life. Such considerations are important for those concerned with developing the capacities of workforces, particularly for the many, perhaps the majority, of those individuals who work and learn in relative social isolation.

\section{Learning vocational practice in relative social isolation}

There has been great interest for a long time in understanding how individuals learn in circumstances where more experienced or expert partners are available to assist. These circumstances are seen as almost the standard way in which learning of socially derived knowledge occurs. The strongest association is perhaps that between learners and the people teaching them the knowledge that they are required to learn. Studies of learning through schools, colleges, and workplaces that afford direct support by more knowledgeable partners have dominated the field of inquiry into learning and have, understandably, emphasised the interpersonal process of learning. Yet, we also need models of the much more common learning processes in which workers engage, for instance, when undertaking relatively independent forms of work. In addition, there are salient procedural and conceptual purposes. Procedurally these kinds of circumstances represent those through which most of learning throughout working life likely often progresses. Many, if not most, workers (e.g., shift workers, home workers, workers who are the sole experts in their workplace) work and learn in relative social isolation. In many countries, workers employed in small businesses far outnumber those who work in large enterprises (Coopers and Lybrand, 1995) and who have greater access to more experienced and expert coworkers. Yet, even those working in large organisations often practise and, therefore, learn in situations of low social guidance. For some, the private practice of the classroom, office, surgery, or car or the kinds of engagement with work tasks are beyond the gaze and hearing of more expert others. Given that learning is ongoing through everyday work activities, whenever and wherever workers are engaged in these activities they are learning (Rogoff \& Lave, 1984), albeit often without access to more expert social partners who can interpersonally provide direct guidance. Of course, in most of these situations there will be, by different degree, accessible social forms and practice to observed, listened to and imitated. Indeed, these forms of indirect social guidance are often reported as assisting learning more frequently than expert guidance (Billett, 2001a). Yet, 
knowledgeable partners can provide access to the kinds of conceptual and procedural knowledge individuals are unlikely to learn through discovery alone. Therefore, there is need to understand how those working in the absence of more expert partners can learn the knowledge required for their work, that is usually provided through direct engagement with more expert social partners.

The conceptual salience of understanding how learning proceeds in these circumstances is to advance contemporary accounts of learning. Over the past two decades, much inquiry into and theorising about learning has emphasised the importance of close interpersonal interactions between more and less experienced partners, and joint problem solving that occurs between them as a premise for optimum socially guided development. In particular, many of these accounts have emphasised interpsychological interactions (i.e., those between individuals and social sources, principally other individuals). Drawing on Vygotskian inspired precepts, this paper proposes that these interactions, and in particular, the interpersonal ones, lead to intrapsychological socially derived legacies (i.e., learning). This learning process comprises the knowledge of the more expert partner (e.g., teacher, skilled worker) being made accessible by joint activities and being appropriated by the less experienced partners (e.g., students, novice workers). There are good reasons to emphasise these kinds of interactions in regards to learning to perform occupational tasks. The knowledge required for occupational practice arises from cultural sources, is transformed through history, and is manifested in particular ways in specific workplace situations, because of localised performance requirements. To construct (i.e., learn) this knowledge, individuals need to engage with social partners, artefacts, and practices that provide access to this knowledge. Within Vygotskian derived traditions, this knowledge is seen to be sourced in phylogenesis (the development of the species), shaped into sociocultural practices (e.g., occupations), and engaged with and appropriated through microgenesis (i.e., moment-bymoment learning) that contributes to individuals' ontogeny (i.e., development across a life course) (Scribner, 1985). Yet, the moment-by-moment learning that constitutes individuals' ontogenetic development most commonly occurs in circumstances where expert guidance is not present. Workers are required to secure novel learning outcomes in the absence of expert guidance and often manage to do so (Billett, 2006). Moreover, it has also been shown that much of children's learning before going to school is indirect and independent, premised on active learning and imitation (Bransford, Sherwood, \& Hassellbring, 1985, cited in Pea, 1987), not a product of teaching by others, such as parents. Indeed, across their lives individuals engage constantly in processes of learning in the absence of experts as they participate in and develop the capacities to perform a range of roles (e.g., parenting) in and outside of work. Similarly, the kinds of active engagement with the social world that Vygotsky identified in children's play (Valsiner \& van der Veer, 2000) suggest the potential scope for their learning resided not only in more experienced social partners, but in the child's agency.

Consequently, current accounts of interpsychological processes that are premised on the access to more experienced partners may not be wholly explanatory of much of the learning processes in which individuals engage throughout their lives. Here, it is proposed that in the absence of direct social guidance individuals exercise their personal epistemology more agentically in their engagement with the world beyond them, when engaging in everyday activities in work and other social settings. That is, they not so much as compensate for the absence of experts, but are quite used to and adept at engaging with the social world from which they learn socially derived practices. Perhaps, most strongly when they are interested, individuals exercise their active and strategic capacities for actively extracting meaning from the available social forms and partners, to paraphrase Gibson and Levin (1975). It follows that for workers employed in circumstances of relative social, geographic, or physical isolation, and working in circumstances where more experienced social partners are unlikely to be encountered, there may well be the case for developing workers' capacity and encouraging the workers to exercise a higher level of strategy and intentionality in their construction of knowledge. The findings of an investigation into how small business operators learnt novel conceptual and procedural capacities (Billett, Ehrich, \& Hernon-Tinning, 2003) 
is used to illustrate this point. The study identified the small business operators' interpsychological processes as being largely premised on learner agency and engagement, including a considered engagement with and critical scrutiny of locally available sources of knowledge. Differences in the purposes, scope, and intentionality of learning-related interactions and activities and their outcomes were largely premised on small business operators' agency. Although this investigation identified contributions of social partners and artefacts, the qualities of engagement and critical appraisal characterising these interactions were largely premised on learner agency.

In advancing its case, this chapter first discusses the conceptual bases for considering the active role of learners in constructing knowledge by reviewing some accounts that refer to the agency that individuals employ in learning from the world beyond them. These ideas are then used to illuminate the epistemological and pedagogic practices of small business operators in their learning of new work tasks: those associated with the introduction of a goods and service tax. It was found in this study that, in combination, localised support and the agentic actions of workers are central to their learning in these circumstances. This suggests the means by which other kinds of socially isolated workers might come to know and learn through their working life. Hence, the central role of personal epistemology within interpsychological processes (i.e., those between the worker and the social world) are emphasised here. In conclusion, some considerations for promoting learning in these circumstances are advanced, with a focus on the active processes of observing and listening, the organisation of learning experiences, and the assisting of individuals to develop criticality in their thinking and acting.

\section{Learning and engagements with the social and physical environment}

The processes shaping individuals' learning through engagement with the world beyond them has long been considered within psychological accounts of human development. Many of these accounts emphasise the agentic way in which individuals engage with and construe and construct meaning from what they encounter in the physical and social world beyond them. That is, they are not merely learning what is suggested by sources external to them. Instead, a consistent line of theorising holds that individuals construct knowledge premised on their interpretations and renderings of what they experience. Indeed, some of the earliest psychological accounts emphasise individuals' active role in these processes. Baldwin, Claparede, and Janet in different ways all emphasise the active and person-dependent interpretative role of the individual. Baldwin (1894) proposed that children, from an early age, begin to understand through their dealings with the social world that it can be inconsistent or unpredictable. He claimed this inconsistency in what is afforded them leads to the projective stage in the growth of personal consciousness, which shapes individuals' responses to what they subsequently experience. These variations in responses to experiences from the world beyond them lead to the learning of principles of interpretation. Here arises the prospect for the potential of imitation: the copying of social partners' behaviours through observation. Imitation provides an early example of interpsychological processes, although Baldwin does not use that term. In all, as part of the development of personality, the child learns principles of interpretation. Later, Baldwin $(1898$, p. 6) proposes these processes were underpinned by selective thinking by referring to a broadly accepted view within psychology that "the growth of the mind depends upon the constant reception of new materials-materials which do not repeat from experiences simply, but constitute in some sense 'variations' upon them." Hence, the relations between the person and the social are construed and constructed by the individuals, and are mediated by what arises through the individuals' personal histories. Janet , according to Piaget (1968), proposed that a distinction must be drawn between 'primary action' or the relation between subject and object (intelligence, etc) and 'secondary action' or subjects' response to their own actions. Moreover, this reaction, which constitutes elementary feelings, regulates primary actions and moderates the release of energy and intentionality available within the organism. Besides these regulations that shape "the energetics or inner economy of behaviour" (Piaget, 1968, p. 5), Janet proposes that we must consider those factors that "govern its [i.e. behaviour's] ends and values, and such values that 
characterise an energetic or economic interaction with the external environment (p.5)". So, here the locus of engaging with and learning through what is experienced is premised on how individuals direct their intentionality. Similarly, Claparede (cited in Piaget, 1968), proposes that feelings appoint a goal for behaviour, with intelligence providing only the means for that goal to be realised. Hence, Claparede suggests that individuals continually modify their goals for actions and, in doing so, shape (i.e., negotiate) meaning with the world that is external to them. He is held by Piaget (1968) to have concluded that individuals' feelings directs behaviour by attributing a value to its ends, and therefore directs the energy necessary for action premised on its value to the individual. In this way, Claparede is held to refer to readapting what the person experiences, on the basis of their needs and conceptions.

Importantly, these early accounts were advanced before the rise and domination of behaviourism, which as a movement tended to downplay the active role of learners in construing what they experienced independently of what was suggested by the social world beyond the individual. Instead, behaviour was proposed as being a learnt response to a particular stimulus. Indeed, rather than a consideration of mind, observable behaviour became the key emphasis within this school of psychological thought. It was perhaps only with the rise of the cognitive revolution that the dominant psychological view came to reemphasise the importance of accounting for the human processing of what is experienced. Indeed, cognitive psychology made a virtue out of the human capacity to remember and manipulate what was experienced, rather than viewing behaviour as a learnt and therefore predictable response to a specific experience. However, others were exploring these kinds of relationships far earlier than those within cognitive psychology. Piaget (1968), for instance, offered accounts that emphasised the particular kinds of negotiations that occurred when individuals encountered novel experiences.

Indeed, to explain these active processes of meaning making, Piaget (1968) had advanced the concept of equilibrium: the individual actively seeking to overcome disequilibrium. Within this account of active meaning making, assimilation was used as a term to describe individuals' process of aligning what they experienced with what they already knew or had learnt. That is, this sense-making was shaped by previous engagements with the same or similar objects. Accommodation, however, was the individual making sense of a new experience through developing new categories of knowledge and ways of knowing, often through elaborating or extending what they already know. Piaget (1968 p. 7) proposed that, "every relation between a living being and the environment has its particular characteristic; instead of submitting passively - modification by imposing on it a structure of its own.” It is noteworthy that Piaget's work is described as genetic epistemology, not psychology, thereby emphasising an active engagement with sources of knowledge. Importantly, Piaget's central concept of equilibrium was framed by concerns about how persons negotiated contributions from both the physical and social world beyond them. Consequently, it has a strong emphasis on the presence and activities of a personal epistemology. In these ways, rather than emphasise either the personal or the social contribution, the focus of human development was based upon negotiations between subject and object, but included the social world and the world of nature. In this way, both brute and institutional factors (Searle, 1995) were accounted for in these negotiations. It is important to be reminded of these contributions to the process of equilibrium, because Piaget's work is often characterised as being too focused on nature and biological development in particular, and excluding social contributions to that development. Yet, clearly, his accounts included the consideration of social contributions to human development, and individuals' negotiation of them with social partners. Indeed, Piaget's original consideration of these ideas dates back to the 1940s, when he discussed successive processes of equilibrium as being "organised along two dimensions - intrapersonal and social (interpersonal)" (1968, p. 50). Therefore, prior to the rise of the behaviourism, the cognitive revolution, and more recent accounts of sociocultural theories, a range of accounts had emphasised active processes of negotiation between persons and the social and physical environments beyond them. These accounts emphasised the active human role of construing, negotiating, and constructing meaning from what was experienced. Moreover, the kinds of activities described above are analogous to 
what in contemporary terms is described as reflexivity: a capacity to consider one's own responses to particular experiences.

As noted, in Vygotskian inspired traditions, relations between the social world and the individual are referred to as interpsychological processes (i.e., between the person and the social world) that lead to intrapsychological outcomes (i.e., changes called 'learning' in the individual). Within this tradition, human development (i.e., learning) is seen as arising from individuals engaging with social partners, cultural forms, and norms. A key concept attributed to Vygotsky is the zone of proximal development (ZPD). This concept proposes that individuals' capacity to learn richly is premised by engagement with a more knowledgeable partner who can extend the scope of the individuals' learning through joint problem-solving. That is, because they know more than the novice, more experienced partners can open possibilities, options, and understandings for learners. In this way, dyads such as those between parent and child, teacher and student, and tradesperson and apprentice are seen to epitomise models of human development based upon access to proximal guidance, and in particular models for learning what Vygotsky (1978) referred to as scientific knowledge. These premises are emphasised in views of learning through apprenticeship-like arrangements (Brown \& Palinscar, 1989; Collins, Brown, \& Newman, 1989; Lave \& Wenger, 1991).Within the Vygotskian tradition, and possibly directly from is also an acceptance of the importance of engagement with the brute world. Indeed, Vygotsky deliberately adopted biological concepts and applied them to the social and cultural genesis of knowledge and human development, because he wanted to emphasise the social contributions to knowledge. For instance, terms such as proximal (i.e., close) and distal (i.e., distant), and also phylogeny (i.e., the development of the species) and ontogeny (i.e., personal development across a life course) were appropriated from their biological origins to inform processes that are inherently cultural and social.

However, these accounts' emphasis on the social and collective contributions to human development have been advanced in the past two decades possibly at a cost of considerations of humans' active thinking and responding to what they experience. Much of this emphasis on the immediate social contribution to cognition was directed as a correction for the dominance of cognitive theory, which emphasises the importance of humans' manipulation of knowledge, as in conception of expertise (Ericsson \& Lehmann, 1996; Glaser, 1989), and a downplaying of the social and physical world's contributions. However, beyond sociocultural theory other perspectives that have a strong cultural and social orientation propose a more central and negotiated role for individuals. For instance, the cultural psychologist Valsiner (1998, p. 393) proposes that "most of human development takes place through active ignoring and neutralisation of most of social suggestions to which the person is subjected to in everyday life". According to this view, the negotiation with the social world is essential to buffer individuals' personalities against the constant demands of social suggestions. He continues:

Hence, what is usually viewed as socialisation efforts (by social institutions or parents) is necessarily counteracted by the active recipients of such efforts who can neutralise or ignore a large number of such episodes, aside from single particularly dramatic ones. (p.393)

Here, Valsiner suggests that there are real limits to potency of the social suggestion and the degree to which it can shape the core human cognition. Such considerations are important given the role that personal constructions of events play in thinking and acting and how these constructions are also shaped through individuals' earlier experiences (Gergen, 1994). In this way, not only is personal history important, but also the agency of the individual in utilising and exercising the legacy of that personal history or ontogeny in their ongoing microgenetic development. Given the social and cultural emphases in Vygotskian inspired accounts of human development, perhaps surprisingly, it seems that Vygotsky concluded that social guidance was secondary to individual agency in the development of psychological functions. In referring to children’s play, he noted: 
In play, the child is always higher than his average age, higher than his usual everyday behaviour; he is in play as if a head above himself. The play contains, in a condensed way, as if in the focus of a magnifying glass, all tendencies of development; it is as if the child in play tries to accomplish a jump above the level of his ordinary behaviour. ... Play is the resource of development and it creates the zone of nearest development. Action in the imaginary field, in the imagined situation, construction of voluntary intention, the formulation of life plan, will motivate -- this all emerges in play. (Vygotsky, 1966, 74-75, translated and cited in Valsiner, 2000, p.43)

What is suggested here is that not only are individuals' interest and volition central to their development, but also that the scope of that development is shaped as a much by the agency of the learner as by other partners. These propositions might seem quite distinct from the widely accepted accounts of Vygotsky-derived theorising. Yet, the founder of cultural historical activity theory, Cole (2002), also claims that in learning and remaking cultural practices individuals' agency is paramount. He reports that he is unable to assist his education students learn how to manage classrooms in turbulent American high schools. Instead, he suggested that these students need to determine what works in that particular school by themselves. In doing so, he suggests that the historically developed cultural practices of classroom management that have been developed and refined over time will not be helpful for these novice teachers. Moreover, the kind of guidance which he might provide as their teacher would also be insufficient. Instead, they had to largely work it out for themselves in uncertain and often difficult circumstances. Beyond individuals' learning, these propositions also suggest that individuals play a central role in remaking cultural practices such as classroom management. It is the application of personal agency when enacting culturally and socially derived practices to particular situations that is generative of the kinds of practices that are undertaken and are being remade through the application and potentially transformed through their enactment.

In all, these accounts suggest that the intentional, active, and focussed engagement that constitutes the process of learning and remaking of practice is shaped by individuals' interests and capacities that comprise their personal epistemologies. Adopting such a concept provides a base to understand learning through and for work as a more active and personcentred process than many recent accounts propose. It also assists understanding of how new learning is developed by those engaged in relatively isolated social circumstances.

\section{Small-business operators' personal epistemologies}

To elaborate the character of these epistemologies, and how they shape learning through working life in different ways, it is helpful to draw on investigations of learning through work. The particular instance discussed here is from businesses whose workforces are small and may also lack the kinds of direct social guidance by experts often found in workplaces with larger workforces. So, unlike workplaces where there are more experienced or expert coworkers to observe, and with whom to engage to discuss and evaluate work tasks, small businesses often lack such accessible sources of knowledge and guidance. Consequently, there arises a question about what kind of interpsychological processes workers in small businesses engage when seeking to learn new tasks. Given the lack of direct social guidance, to what degree do these workers have to be more personally agentic and directed in their thinking, acting, and learning? That is, do these workers have to compensate for the absence of easily accessible socially derived knowledge from experts and have to develop a more agentic personal epistemology?

The accounts here are derived from a study of how small-business operators learnt to implement the goods and service tax during its introduction in Australia (Billett et al., 2003). Unlike in Europe, in Australia, small businesses are those with 10 or fewer employees and include sole operated businesses. Given the well-reported reluctance of small-business operators to participate in vocational education programs (Coopers and Lybrandt 2005), this study aimed to understand how these operators acquire new knowledge and respond to 
innovations. The procedural outcomes of this study aimed to be helpful in suggesting the kinds of models of learning support that might be most appropriate for such workers One form of learning support would be assisting workers to find ways to secure access to to forms of localised support that are appropriate for and informed about their particular circumstances and understood the particular learning that these small-business operators require. However, the study also drew attention to conceptual considerations for learning in situations that lacked direct access to more informed social partners (i.e., proximal guidance). The procedural concerns come together with conceptual development. As noted, current understanding about learning through work situations is largely premised on richly social affordances, including the availability of more informed social partners. Less is known about learning through work in the absence of these kinds of dyads and other forms of social partnerships.

The study referred to here used interviews and case studies of 25 small businesses to identify the processes through which small-business operators learnt how to implement the goods and service tax in their businesses. The small business operators were guided through a series of questions about: (i) their business; (ii) the preparations they undertook before the implementation of the goods and service tax; (iii) the scope of learning that was required by the informant; (iv) how that learning occurred; (v) the relative contributions of a range of learning supports; and (vi) perceptions of the ideal way that this task could have been learnt. Undertaking the task of implementing the goods and service tax comprised, for many businesses, a significant body of new learning. It required understanding the conceptual premises of administering the tax, which were not always straightforward, and the procedural means for calculating, gathering, and forwarding the tax to the Australian Taxation Office; for many small businesses this requirement meant they had to address for the first time electronically organised business management procedures. Despite being a nationally uniform process, the implementation of the goods and service tax meant quite different things for each of the businesses interviewed. This was because of the breadth and complexity of the taxation requirements within and across business activities. Some small businesses had access to different kinds of assistance outside of their business. These included business consultants and accountants who were employed to manage the acquisition of this new knowledge, or to do it for the business operators. Others used their bookkeepers to learn about and implement this new requirement, thereby avoiding having to learn about and implement it themselves. For others still, however, the learning process was essential. For some, developing these capacities was necessary to be free themselves from the burden of employing accountants, consultants, and others to do this work. Because it was a national initiative, there was also a range of more distant forms of support provided by the government, and industry groups and local chambers of commerce et cetera to help small-business operators understand the principles, processes, and obligations associated with their administration of this tax. Importantly, this process had to be implemented by all Australian businesses, except the very smallest, by the beginning of the new financial year. Consequently, learning about this tax and the processes supporting it were being widely discussed in many forums and by business operators who had to learn its principles and practices to meet their legislated obligations and maintain the viability of their businesses. Therefore, it is a topic for discussion and evaluation across many forums with which these workers engage, particularly outside of the small businesses.

The interviews were conducted two years after the implementation of the goods and service tax and, as such, allowed the operators to reflect, retrospectively, upon their experiences. The interviews provided data that permitted identification of available forms of support outside of operators' workplaces, and the degree and ways by which these were reported as being helpful to these small businesses. In general, support was most helpful when the source of that support understood the nature of the specific business and could identify the particular implications of the goods and service tax upon that business. Support was least valued when it offered principles without being able to advise how the tax would impact on the particular business. Significantly, in terms of outside support, trust was identified as being an essential quality in judging the support as being helpful. Thus, there was an active 
consideration by these learners (i.e., business operators) of the bases on which information was being provided. Importantly, judgements about the worth of the forms of support with which individuals engaged arose from their engagement with and critical considerations of these forms of support. Yet, this trust and view of the worth of informants was developed through active consideration of and appraisal by the small-business operators. These operators claimed to be engaged in seeking and accessing advice, and also making decisions about the veracity of that advice. They reported actively listening to speakers talk about the goods and service tax when attending meetings sponsored by local commerce groups, in order to assess the worth of what was being stated, and to asses and test their own knowledge of these schemes. Hence, these operators were not passive recipients of such information, rather, they tested out its applicability, standing, and value, in ways analogous to what is referred to as critical appraisals of knowledge. Thus, even when engaging with other sources of information, these workers reported being agentic, critical, and comparative. That is, they were engaged in a highly active and strategically focused learning process characterised by the exercise of an agentic personal epistemology.

Beyond engaging with others, the small-business operators also reported being pragmatic and selective in their efforts at conscious learning. They reported trying to identify what they needed to know and then direct their energies in very selective, but active, ways to learn what they needed to know, and for the specific requirements of the small-business. For instance, one proactive learner was an entrepreneur who owned a number of businesses of different kinds. Business profitability, not the kind of business or professional practice, was his key motivation. In contrast, two of the small businesses comprised professional practices (i.e., a veterinarian surgery and an optometrist). Both of these professionals reported finding as quite uninteresting the processes of business administration and, in particular, the accounting components and requirements of the business. They were more interested in their professional practice and hired bookkeepers to do their administrative and accountancy work. Hence, their approach to goals for learning and efforts were commensurate with their interests. In short, they delegated the majority of the responsibility to their paid bookkeepers. They only wanted to know what they had to understand about the principles under which the goods and service tax operated. So, their focus on, approach to, and engagement in learning this task was relative to and quite distinct from those of the entrepreneur, for instance. However, what was common was that these individuals directed their interests and focuses towards their particular ends. Important here is the selective nature of these workers' epistemological actions.

Then, as noted, there were small-business operators who were keen to learn how to administer the goods and service tax in order to avoid the expense of accountants and bookkeepers that had arisen during the implementation phase. These individuals, like the entrepreneur, were often highly proactive, engaged, and eager to learn the processes of administering this tax. For them, the intention for learning was about reducing the cost of running their business and assisting in its financial viability. Consequently, they were pragmatic, engaged, and interested in what they needed to learn in order to effectively adopt this innovation and thus remove the financial burden of paying accountants and bookkeepers. Then, there was one business owner, a bookshop owner, who had few local sources of advice (i.e., proximal guidance). He actively and selectively sought advice from and engaged in reciprocal learning with another bookshop owner in another state, communicating electronically in sharing information about what the goods and service tax meant to their businesses, and how best they could implement it with little or no impact on their businesses. In some ways, this process builds upon existing practice by bookshop owners who often use their own networks to swap stock in order to fulfil customer requests. In all, these examples demonstrate the ways in which personal agency, which extended to the identification of credible sources of information, was enacted by workers who had to acquire new knowledge in the absence of immediate expertise and guidance (Billett et al., 2003).

However, the exercise of personal epistemologies was not always effective. One small-business owner, who was quite socially and geographically isolated, relied upon his own resources and expertise. These comprised quite rudimentary, albeit effective, business 
aids including a manual entry system to note sales and manage stock. However, the advent of the goods and service tax required all small-business operators to use a software package to administer their businesses and fulfil their taxation administration obligations. This particular business operator had never used a computer, had no experience with business management software, and did not know how to translate his current business management strategy into one based upon the use of computer. However, his individual and self-directed approach to learning concepts and procedures (epistemological adventures, if you like) led to a range of difficulties, embarrassment, and, ultimately, high levels of anxiety. In all, his capacities and approach (i.e., personal epistemology) were inadequate for the task to be learnt, as was the degree and means by which he engaged with others who could assist and help him implement his business management systems. Essentially, the gaps in his knowledge were too great to be closed by discovery learning alone. He required the assistance of particular kinds of experts to assist him to secure the very specific kinds of knowledge needed to operate the technology effectively. Yet, it seems also that his beliefs and values, and perhaps social competence, rendered him reluctant to engage with others to secure sources of advice and assistance with learning new concepts and procedures. Consequently, the inadequacy of his personal epistemology, including not working to overcome his socialisation, was limiting the process and scope of what was, for him, necessary learning.

Hence, while providing illustrative instances of agentic learning for particular purposes, this paper needs to state the consequences of an inappropriate reliance upon personal epistemologies. These epistemologies and their exercise are not of unqualified effectiveness. Instead, they need to be seen as being used selectively, and in ways that depend upon the particular qualities of the learner and the scope of the learning to be undertaken. At their best, these personal epistemologies were both driving and guiding the process of trying to make sense of this new business requirement in ways consonant with Piagetian accounts of securing equilibrium and viability, and also with the kinds of critical and reflexive processes that have been identified as being necessary in recent accounts of lifelong learning, for instance (Dyke, 1997; Edwards, Ranson, \& Strain, 2002). These workers were trying in an active way to understand what was required of them, and were guided by desires to be clear about the process and its requirements, and were deploying their way of seeing and engaging with the world, making sense, and responding to the social world in a highly active way. Yet, there can be no guarantee that the learning can be negotiated by individual efforts alone, particularly if the gap between what the individual knows and what they need to learn is great. There is a point at which the limits of personal agency are understood and guidance by more expert others becomes essential, as the example above demonstrates. In these ways, personal epistemologies were exercised to understand the knowledge required for these work tasks, and the boundaries (e.g., scope, limitations, strengths, and weaknesses) of what the individuals know. However, within this mix is the need for individuals to know at what point it is necessary to engage with others to secure kinds of knowledge that they need to learn.

If follows, therefore, that personal epistemologies are seen as being a premise to understand the intentional, agentic, and selective learning in which these small-business operators needed to engage. Perhaps most noticeable in their accounts, is how they had to engage proactively and critically, not accepting the worth of advice received from others, but appraising that advice in terms of its application to the particular issues they had to address and the circumstances in which those responses had to occur. Yet, in all of this, there is the sense of these workers reaching out to secure new knowledge, identify viable sources of information, and actively appraise that information in the absence of the kinds of close guidance that is available elsewhere. As discussed earlier, these processes are distinct from individuals' manipulation of their existing knowledge, which would never been sufficient in these circumstances, because the knowledge to be learnt had to be secured from elsewhere. Yet, more than perhaps what is proposed in contemporary sociocultural accounts, there is also evidence here of an engagement which seems to be quite distinct from that proposed to occur between experts and novices. The learners here were not looking directly to experts to provide the knowledge they needed. Instead, they engaged with them in a way that was testing and pressing the expertise that was available to them. All of this suggests that accounts of 
intrapsychological processes require further elaboration in order to explain kinds of learning processes that can be found in these accounts. The zone of nearest or proximal development was that being created often by the learner in seeking to establish the problem space to which they needed to respond, and also actively identifying and locating interlocutors from whom to secure the kinds of understandings and procedures that they needed to learn. Indeed, it seems as though these learners delineated the scope of the learning that they desired, and the degree by which others could assist them secure the knowledge that they needed to learn.

If follows that the kinds of models of human resource development that might be afforded to such workers would likely have a design and be enacted in ways different from those proposed in many current accounts of learning new knowledge through work. That is, models of learning through work in social isolation ought to emphasise the active engagement of the learner rather than the guidance of an expert.

\section{Supporting learning in situations of limited social guidance}

This book has as its rationale advancing key considerations for advising and guiding human resource development practitioners in assisting workers learn the knowledge they need to secure for effective work practice. Here, it is proposed that in the absence of more expert coworkers, particular approaches to learning are required. These are premised on the agentic epistemological activities of learners. What needs to be stated upfront is that social guidance is provided in a range of ways as organised and selected by the learners, not only through the close guidance of a more expert coworker. Indeed, in a series of studies across a range of industries and workplaces, people were found to learn through everyday work activities typically and largely in the absence of direct guidance (Billet, 2001a). Perhaps the most commonly cited forms of support by workers across these studies were engaging in work activities (e.g., "just doing it"), observing and listening to others, and the contributions of the physical workplace setting. In essence, these workers reported what has been found in anthropological studies of the learning of culturally derived practices, which is that the majority of that learning occurs through processes that do not involve the close guidance of more expert partners (Lave, 1990). Consistent with findings of the anthropological studies were the workers' reports that the active engagement in tasks and with the physical and social environment of the workplaces in which those tasks were undertaken provided the goals for, procedures of, and premises for undertaking that work (Billett, 2001a). In short, the mediation of individuals' cognitive capacities fuelled by their interests and values largely shaped the goals for and processes of learning in these physical and social environments. Yet, having said this, there is also recognition in both the anthropological and workplace studies that there are limits to this self-directed and personally mediated form of learning. For instance, anthropological studies identify instances of teaching knowledge that would not be secured through discovery alone. One example was the need of Micronesian fishermen to learn star patterns by which to navigate at night (Pelissier, 1991). Here, jetsam and pebbles on the beach were used to illustrate the position of stars and help the fishermen identify them. Also, in the workplace learning studies, it was found necessary to use a range of pedagogic strategies to overcome concerns about the development of specific procedures and conceptual understanding that were not going to be learnt effectively through practise alone.

Consequently, there are both strengths and limitations to the exercise of personal epistemologies in learning through and for work. Both strengths and limitations are likely found in the extent of the individuals' domain-specific knowledge, that is, their knowledge of a particular domain of activities, such as their occupation or business, and the extent of the gap between their personal domain of knowledge and the knowledge that needs to be learnt to effectively undertake the new tasks. Hence, in considering approaches to assisting workers learn in this way, a starting point is the understanding of the gap between what workers already know and what they need to know in order to effectively complete the new task. So, the scope or the zone of the new learning becomes an essential consideration. However, the scope of the learning, rather than being somehow fixed, is shaped by the extent and depth of individuals' knowledge and the gap between that and what has to be learnt. Thus, as so many have suggested before (Ausubel \& Novak, 1978), an important starting place is understanding 
learners' knowledge and readiness to engage in what needs to be learnt. For some, such as the accountants and bookkeepers, in this study, the new tasks represented something which was easily negotiable using their personal epistemologies and domain-specific knowledge. However, for the individual lacking the financial, taxation, and information technology knowledge required to operate a business management system, the scope of the task to learn that new knowledge might be quite large and impossible to negotiate without the assistance of more knowledgeable others. Consequently the first task is to decide whether the scope of the learning required is something that can be negotiated by the individual agentically, or requires the assistance of others, and the degrees by which such support is required. However, not only is this task likely to be person dependent, it is also likely to be situationally specific. Earlier studies have indicated that the particular performance requirements for workplaces differ quite markedly (Billett, 2001b). So, it is important to appraise the individuals' competence and readiness against the requirements of the domains of activities that they will be required to learn, not some uniform standard.

Secondly, there is a need to understand the kinds of knowledge that are required to be learnt (i.e., conceptual, procedural, and dispositional) and the best means by which these can be developed more generally. Hence, individualised considerations of the kinds of knowledge that are required to be learnt, and what kind of support is most likely to be helpful, are required. For instance, particular emphases on conceptual, procedural, or dispositional dimensions of the knowledge required for effective performance may well require particular kinds of interventions. The development of conceptual capacity might require making accessible to these learners knowledge which otherwise remains hidden from them. The development of procedural capacity likely will require expert engagement and opportunities to practise, refine, and hone, so that the learner can progressively realise more mature approximations of the procedures needed to effectively enact those tasks. In addition, dispositional development might well arise from opportunities to observe effective models. While all of this might sound demanding, potentially, for many workers the need for this learning support will be through exceptions. This is because much of that learning can progress without the need for such interventions because it arises through observation, imitation, and practise that assists that imitation become increasingly mature approximations of the tasks to be learnt. All of this is directed by individuals' personal epistemologies.

In concluding, the key point made here is that much of our learning arises without the need for direct guidance. The quality about learning appears to be premised upon the degree by which learners engage actively, intentionally, and with criticality. The agency of the learner can do much to access the kinds of knowledge that are available in the social world and need to be constructed by the learner and, in doing so, close the gap between their personal domain of knowledge and that required for effective performance in their workplace. Consequently, there is no need for constant access to expert guidance, rather, this access is needed only when expert guidance is required. Therefore, at the same time it is important that individuals' personal epistemologies be opened to and aware of their limits in securing knowledge that is outside of the zone that constitutes the scope of learning that they can realise agentically. It is in the areas beyond that zone that they will need to access guidance by more expert partners.

References

Ausubel, D. P., \& Novak, J. D. (1978). Meaningful reception learning and retention. In D. P. Ausubel, J. D. Novak, \& H. Hanesian (Eds.), Educational psychology: A cognitive review (pp. 114-160). New York: Holt Reinhardt and Winston.

Baldwin, J. M. (1894). Personality-suggestion. Psychological Review, 1, 274-279.

Baldwin, J. M. (1898). On selective thinking. The Psychological Review, 5(1), 1-24.

Billett, S. (2001a). Learning in the workplace: Strategies for effective practice. Sydney: Allen and Unwin.

Billett, S. (2001b). Knowing in practice: Re-conceptualising vocational expertise. Learning and Instruction, 11(6), 431-452. 
Billett, S. (2006). Work, change and workers. Dordrecht: Springer.

Billett, S., Ehrich, L., \& Hernon-Tinning, B. (2003). Small business pedagogic practices. Journal of Vocational Education and Training, 55(2), 149-167.

Brown, A. L., \& Palinscar, A. M. (1989). Guided, cooperative learning and individual knowledge acquisition. In L. B. Resnick (Ed.), Knowing, learning and instruction: Essays in honour of Robert Glaser (pp. 393-451). Hillsdale, N.J: Erlbaum \& Associates.

Cole, M. (2002, April). Building centers of strength in cultural historical research. Paper presented at the Annual Meeting of the American Educational Research Association, New Orleans.

Collins, A., Brown, J. S., \& Newman, S. E. (1989). Cognitive apprenticeship: Teaching the crafts of reading, writing and mathematics. In L. B. Resnick (Ed.), Knowing, learning and instruction: Essays in honour of Robert Glaser (pp. 453-494). Hillsdale, NJ: Erlbaum \& Associates.

Coopers and Lybrand. (1995). Small business: A review of training evaluation and effectiveness. In Enterprising Nation (Research Report Volume 2. Document no. TD/TNC 49.73). Canberra, Industry Task Force on Leadership and Management Skills: Australian Government Publishing Service.

Dyke, M. (1997). Reflective learning as reflexive education in a risk society: Empowerment and control? International Journal of Lifelong Education, 16(1), 2-17.

Edwards, R., Ranson, S., \& Strain, M. (2002). Reflexivity: Towards a theory of lifelong learning. International Journal of Lifelong Education, 21(6), 525-536.

Ericsson, K. A., \& Lehmann, A. C. (1996). Expert and exceptional performance: Evidence of maximal adaptation to task constraints. Annual Review of Psychology, 47, 273-305.

Gergen, K. J. (1994). Realities and relationships: Soundings in social construction. Cambridge, Mass: Harvard University Press.

Gibson, E. J., \& Levin, H. (1975). Psychology of reading. Cambridge, Mass: MIT Press.

Glaser, R. (1989). Expertise and learning: How do we think about instructional processes now that we have discovered knowledge structures? In D. Klahr \& K. Kotovsky (Eds.), Complex information processing: The impact of Herbert A. Simon (pp. 269-282.). Hillsdale. NJ: Erlbaum \& Associates.

Janet, P. (1930). Pierre Janet. In C. Murchison (Ed.), A history of psychology in autobiography (pp. 123-133). Worcester, MA: Clark University.

Lave, J. (1990). The culture of acquisition and the practice of understanding. In J. W. Stigler, R. A. Shweder \& G. Herdt (eds). Cultural psychology (pp. 259-86). Cambridge. U.K: Cambridge University Press.

Lave, J., \& Wenger, E. (1991). Situated learning: Legitimate peripheral participation. Cambridge, UK: Cambridge University Press.

Pea, R. D. (1987). Socializing the knowledge transfer problem. International Journal of Educational Research, 11(6), 639-663.

Pelissier, C. (1991). The anthropology of teaching and learning. Annual Review of Anthropology, 20, 75-95.

Piaget, J. (1968). Six psychological studies. New York: Vintage.

Rogoff, B., \& Lave, J. (Eds.). (1984). Everyday cognition: Its development in social context. Cambridge, Mass: Harvard University Press.

Scribner, S. (1985). Vygostky's use of history. In J. V. Wertsch (Ed.), Culture, communication and cognition: Vygotskian perspectives (pp. 119-145). Cambridge, UK: Cambridge University Press.

Searle, J. R. (1995). The construction of social reality. London: Penguin.

Valsiner, J. (1998). The guided mind: A sociogenetic approach to personality. Cambridge, Mass: Harvard University Press.

Valsiner, J., \& van der Veer, R. (2000). The social mind: The construction of an idea. Cambridge, UK: Cambridge University Press.

Vygotsky, L. S. (1978). Mind in society: The development of higher psychological processes. Cambridge, Mass: Harvard University Press. 
